\title{
THE MEETING OF THE AMERICAN ASSOCIATION.
}

THe annual meeting of the American Association for the Advancement of Science was held at Madison, Wis., August 16-23, William Harkness of Washington presiding. In point of numbers the meeting was a disappointment, only 288 having finally registered; but in point of scientific interest and social intercourse it will rank among the most successful. The situation of Madison is especially favorable for the comfort of a gathering in the heated term. 'The citizens of the place were cordial in their reception of the Association and did much for its entertainment, while the excursion to the Dells of the Wisconsin on Saturday was a notably pleasant feature.

The attendance upon the meetings of the section in mathematics and astronomy was smaller than usual, but the proportion of papers of a distinctively mathematical character was comparatively great. The officers of the section were C. L. Doolittle, South Bethlehem, Pa., Vice-President; C. A. Waldo, Greencastle, Ind., Secretary; Geo. C. Comstock, Madison, Wis., Councilor ; A. S. Flint, Madison, Wis., E. W. Hyde, Cincinnati, O., Malcolm McNeill, Lake Forest, Ill., together with Vice-President and Secretary, Sectional Committee; Frank H. Loud, Colorado Springs, Member of Nominating Committee; Rudolph Siemon, Fort Wayne, Ind. ; F. W. Kuhne, Fort Wayne, Ind.; H. B. Hedrick, Washington, D. C., together with Vice-President and Secretary, Sectional Nominating Committee.

The following papers were presented :

1. Variations of latitude; Vice-Presidential address. C. L. Doolittle, So. Bethlehem, Pa.

2. A construction for the imaginary points and branches of algebraic loci. Frank H. Loud, Colorado Springs, Colo.

3. The screw as a unit in a Grassmannian system of the sixth order. E. W. Hyde, Cincinnati, Ohio.

4. Applications of the generalized logarithmic theorem. Alex. Macfarlane, Austin, Texas.

5. On the inscription of regular polygons. L. E. Dickson, Austin, Texas.

6. Latitude determination at Bethlehem, 1892-93. C. L. Doolittle, So. Bethlehem, Pa.

7. A determination of the constant of aberration by a modified form of the Loewy method. Geo. C. Comstock, Madison, Wis.

8. On the possibility of the algebraic solution of the general equation of the fifth degree. Mansfield Merriman, So. Bethlehem, Pa.

9. Space. S. S. Laws, Columbia, S. C. 
No. 1 was a careful and thorough résumé of progress in the solution of the vexed problem of periodic and permanent latitude variations. To the final solution of this problem Mr. Doolittle has personally contributed data of great value by his persistent and arduous labors at Bethlehem.

No. 2 was a proposition worked out in considerable detail for the construction of a locus of two complex dependent variables.

No. 3 was a continuation of the author's labors in interpreting Grassmann's ideas, in modifying them and making them practical. 'The paper is a clear and simple discussion of the units that would arise and their relation to each other in a space popularly known as one of six dimensions.

In the absence of the authors a résumé of papers 4 and 5 was presented by the Secretary. Mr. Macfarlane has been working upon a modified Quaternion analysis. Some of his papers on this subject have appeared in recent volumes of the Proceedings of the American Association. The present paper applies one of his general results to a derivation, simpler and more direct than has heretofore been possible, of a number of important trigonometrical series. Mr. Dickson re-examined the subject of inscriptible polygons as presented in Gauss's works, and believes that he has simplified and made available Gauss's material besides adding much that is new.

No. 6 was in a sense a continuation of No. 1. No. ry was presented to the section at the Washburn observatory, which was visited at Mr. Comstock's invitation.

No. 8. was in a sense a continuation of Mr. Merriman's paper of a year ago upon the equation of the third degree. The possibility suggested arises from an analogy in the geometrical construction of the roots of an equation of the fifth degree to those of an equation of the third and fourth degrees.

No. 9 was a metaphysical. discussion.

No final decision was reached as to the place of the next annual meeting. The matter was left in the hands of a committee with the probability that Brooklyn will be chosen. If not Brooklyn, then some New England city. August 15-23 was set as the time. It is generally understood that in 1895 the Association will visit San Francisco. The President of the next meeting will be D. G. Brinton of Media, Pa.

The sectional officers chosen for 1894 are the following: Vice-President, Geo. C. Comstock, Madison, Wis.; Secretary, Wooster W. Beman, Ann Arbor, Mich.

C. A. Waldo. 